\title{
Pioglitazone Ameliorates Neuron Loss in the Cortex after Aluminum-Treatment in Rats
}

\author{
Ali Rafati, ${ }^{1,2}$ Hajar Yazdani, ${ }^{2}$ and Ali Noorafshan ${ }^{1,3}$ \\ ${ }^{1}$ Histomorphometry and Stereology Research Centre, Shiraz University of Medical Sciences, Shiraz, Iran \\ ${ }^{2}$ Physiology Department, School of Medicine, Shiraz University of Medical Sciences, Shiraz, Iran \\ ${ }^{3}$ Anatomy Department, School of Medicine, Shiraz University of Medical Sciences, Shiraz, Iran \\ Correspondence should be addressed to Ali Noorafshan; noora@sums.ac.ir
}

Received 8 March 2015; Revised 21 May 2015; Accepted 24 May 2015

Academic Editor: Jeff Bronstein

Copyright (c) 2015 Ali Rafati et al. This is an open access article distributed under the Creative Commons Attribution License, which permits unrestricted use, distribution, and reproduction in any medium, provided the original work is properly cited.

\begin{abstract}
The objective was evaluation of the effects of pioglitazone on medial prefrontal cortex (mPFC) of the rats exposed to aluminum (Al). Al induces structural changes in several brain regions, including mPFC. Pioglitazone is an agonist of peroxisomal proliferator activated receptor gamma. Male rats were randomly assigned to control, Al-treated $(10 \mathrm{mg} / \mathrm{kg} / \mathrm{day})$, and Al + PIO-treated groups $(\mathrm{Al}+40 \mathrm{mg} / \mathrm{kg} /$ day). After 56 days, the right mPFCs were removed. Then, the volume of $\mathrm{mPFC}$ and its subdivisions, volume of vessels, and total number of neurons and glia were estimated using stereological methods. The results showed $13-38 \%$ decrease in the volume of the mPFC and its subdivisions, mainly in the infralimbic region $(P<0.02)$. Besides, the volume of the vessels reduced by $47 \%$ after Al-treatment $(P<0.02)$. The total number of the neurons and glial cells was also reduced $(40 \%$ and $25 \%$, resp.) in the $\mathrm{Al}$-exposed rats in comparison to the control ones $(P<0.02)$. Treatment of the animals with $\mathrm{Al}+\mathrm{PIO}$ ameliorated the neuron loss and no improvement was seen in other parameters $(P<0.02)$. It can be concluded that treatment of the rats with PIO could ameliorate the neuron loss in the mPFC of the Al-treated animals.
\end{abstract}

\section{Introduction}

Aluminum ( $\mathrm{Al})$ is an abundant metal in the environment. It is a component of cookware, utensils, medicines such as antacids, cosmetics such as deodorants, and food additives. Some foods, especially corn, yellow cheese, salt, herbs, spices, and tea, might also contain $\mathrm{Al}[1,2]$. In addition, industrialized civilizations use alum (aluminum sulfate or aluminum potassium sulfate) as flocculants in purification of drinking water. This enabled distribution of large volumes of drinking water to millions of urban consumers and allowed easy entrance of $\mathrm{Al}$ into the body via gastrointestinal tract $[1,2]$. $\mathrm{Al}$ is particularly accumulated in the liver and different parts of the brain. Evidence has proved that chronic intake and metabolism of Al compounds could account for Alzheimer's disease $[1,2]$.

Aluminum concentrations were found to be extensive in the hippocampal region and also frontal cortex of the Alzheimer patients [3]. The hippocampal region has received a great attention. Nevertheless, a limited number of studies have assessed the effects of $\mathrm{Al}$ on prefrontal cortex (PFC). However, PFC is the cerebral cortex located in front of the frontal lobe. Functionally, PFC is believed to be involved in monitoring of actions, decision making, memory, motor planning, movement, and reward [4]. PFC is involved in cognition and seems to play a role in dementia associated with Alzheimer. Therefore the present study focused on the evaluation of the prefrontal cortex structure [3]. A previous study revealed reduction of glial fibrillary acidic protein levels and impairment of astrocytes function in the rats' cerebral cortex after Al-treatment [5]. Kim (2003) also showed impaired expression of neuronal nitric oxide synthase caused by exposure to $\mathrm{Al}$ during the early developmental stage of the brain [6].

Although different neuroprotective agents have been evaluated after Al-exposure, the present study aims to evaluate the effects of pioglitazone (PIO). PIO is an agonist of the peroxisome proliferator activated receptor. Evidence has 
suggested that these receptor agonists may improve some of the histopathological features of Parkinson's disease, optic nerve crush, and spinal nerve crush and cerebral ischemia [7-9]. It has been shown that activation of PPAR induces anti-inflammatory and antioxidant properties in brain. This neuroprotective influence is caused by both cerebral and vascular mechanisms. PPAR activation persuades a reduction in neuronal death by deterrence of oxidative or inflammatory processes involved in cerebral injury [10].

It has been also reported that the vascular effects are the outcome of a decrease in oxidative stress and inhibition of function of adhesion proteins, including the molecules of vascular cell or intercellular adhesion proteins injury [10]. Moreover, PPAR activation might be able to induce healing and regeneration of the vascular endothelium of the brain. In addition, there are reports of neuroprotection in chronic neurodegenerative diseases injury [10].

Expression of the PPAR-gamma has been approved in many anatomical brain regions of the adult mouse including cerebral cortex, caudate, putamen, hippocampus, thalamus, hypothalamus, and brain stem [11]. According to the abovementioned rationales, evaluation of effectiveness of PIO in protecting the vessels, neurons, and glia in the cortex after exposure to a neurodegenerative agent $(\mathrm{Al})$ can be useful for future clinical application. Since the structure of PFC after Alexposure has received less attention, the medial PFC (mPFC) of the rats was evaluated in the first step of this study. In the second step, the protective effects of PIO on mPFC were investigated. Briefly, the study aimed to find responses to the following questions using stereological techniques: How much does the volume of the mPFC and its subdivisions change after Al-treatment? How much does the volume of the vessels change after Al-exposure? How many neurons and glial cells of the mPFC are lost after Al-consumption? Does PIO protect the mPFC structure and its subdivisions after exposure to $\mathrm{Al}$ ? Does PIO protect the vessels, neurons, and glial cells of $\mathrm{mPFC}$ after exposure to $\mathrm{Al}$ ?

\section{Methods}

2.1. Animals and Treatments. In this study, 15 adult male Sprague-Dawley rats $(165 \pm 15 \mathrm{~g})$ were obtained from the Laboratory Animal Center of Shiraz University of Medical Sciences. The Ethics Committee of the University approved the animal experiment (Approval number 92-6789). The animals were housed under standard conditions, room temperature $\left(22-24^{\circ} \mathrm{C}\right)$, and a 12:12 h light-dark schedule and had free access to water and food. The animals were divided into three groups $(n=5)$. Five animals per group were sufficient for the stereological studies and were chosen according to Hyde et al. (2007) [12].

Control group (I) received i.p. injection of $1 \mathrm{~mL}$ normal saline (as a vehicle) daily, (II) Al group received i.p. injection of $1 \mathrm{~mL}$ of the vehicle containing $10 \mathrm{mg} / \mathrm{kg} /$ day aluminum chloride (Sigma Aldrich, Germany) [13, 14], and (III) Al + PIO group received $40 \mathrm{mg} / \mathrm{kg} /$ day of pioglitazone (Sigma Aldrich, Germany) in addition to Al [15]. PIO was administrated by gavages. The treatments were continued for 56 days.
The rationale for selecting the $\mathrm{Al}$ dose was the aluminum intake in adults which is usually $10 \mathrm{mg} / \mathrm{kg} /$ day, but it will increase to hundreds $\mathrm{mg} / \mathrm{kg} /$ day when people receive foods with a high aluminum concentration or aluminumcontaining drugs. Therefore the exact intake of $\mathrm{Al}$ cannot be determined exactly in human being in different countries [16]. Finally, the dose of $\mathrm{Al}$ was selected according to European Food Safety Authority. The Authority reported that the mean dietary contact from water and food in nonoccupational exposed human adults exhibited large variations between different countries and, within a country, between different studies. The measure was reported to range from 1.6 to $13 \mathrm{mg}$ Al per day $[13,14]$. In addition, it should be mentioned that the selected dose has been recommended in animal models to induce neuronal degeneration. It is important in the present research to evaluate the protective effects of PIO on loss of neuronal and glial cells after exposure to the neurodegenerative dose.

The rationale for choosing $40 \mathrm{mg} / \mathrm{kg}$ dose for pioglitazone was based on the research by Almasi-Nasrabadi et al. [15]. They administrated 10,20 , and $40 \mathrm{mg} / \mathrm{kg}$ of PIO to mice receiving scopolamine and found that dose of $40 \mathrm{mg} / \mathrm{kg}$ improved some behavioral performances of the mice [15].

2.2. Tissue Preparation. The rats were anesthetized with ketamine-xylazine (80 and $20 \mathrm{mg} / \mathrm{kg}$, resp.). After transcardial perfusion of the rats with buffered formaldehyde, the brains were uncovered by an incision along the midline of the skull. After that, the right cerebral hemisphere was immersed in buffered formaldehyde for one week and then embedded in the paraffin block. mPFC was recognized according to the atlas of Paxinos and Watson. It located at $4.70-2.70 \mathrm{~mm}$ ventral and $4.70-2.70 \mathrm{~mm}$ dorsal to the bregma [17]. A complete series of coronal sections of $4 \mu \mathrm{m}$ followed by $26 \mu \mathrm{m}$ thickness were obtained and continued along the whole length of the mPFC. Overall, about 8-12 sections with $4 \mu \mathrm{m}$ thickness and 8-12 sections with $26 \mu \mathrm{m}$ thickness were selected from each $\mathrm{mPFC}$ in a systematic random manner. The sections were stained with cresyl violet $(0.1 \%$ in distilled water) in order to estimate the volume of the mPFC and its subdivisions, volume of the vessels, and total number of the neurons and glial cells. It should be mentioned that the glial cells were distinguished from the neurons by their smaller size and lack of a nucleolus and stained cytoplasm.

\subsection{Estimation of the Volume of MPFC and Its Subdivisions.} $\mathrm{mPFC}$ includes three subdivisions, namely, prelimbic (PL), infralimbic (IL), and Anterior Cingulate Cortex (ACC) [17]. Using a projecting microscope, the live images of $4 \mu \mathrm{m}$ thickness sections were evaluated at the final magnification of $24 \mathrm{x}$ according to the rat brain atlas [17]. The boundaries of the mPFC were considered from the most frontal section where the underlying white matter appeared and was sustained on every mounted section up to the presence of the genu of the corpus callosum where decussating fibers could be seen. The volumes were calculated using the Cavalieri method [18, 19]. Briefly, a grid of points was overlaid on the PFC images and 


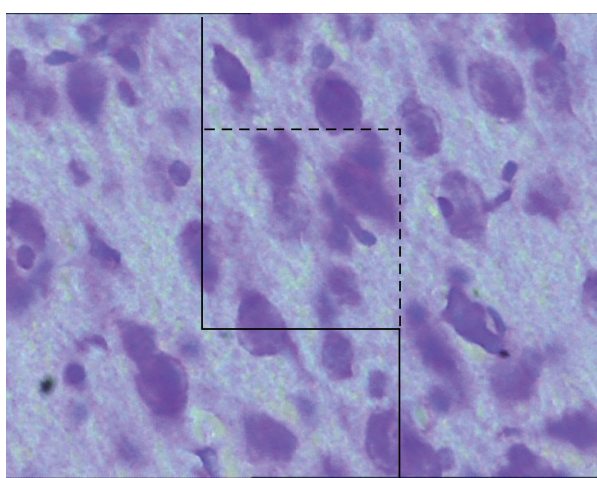

(a)

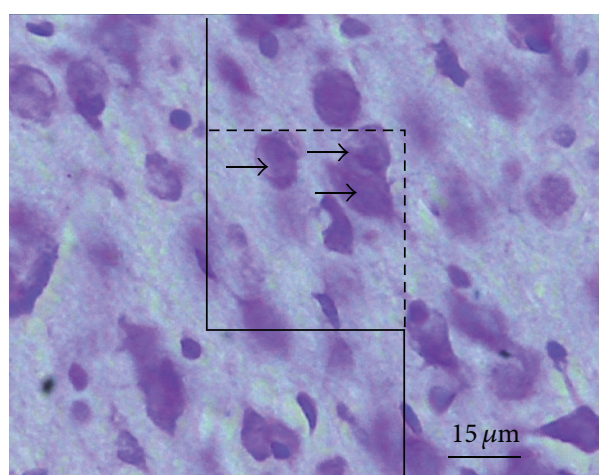

(b)

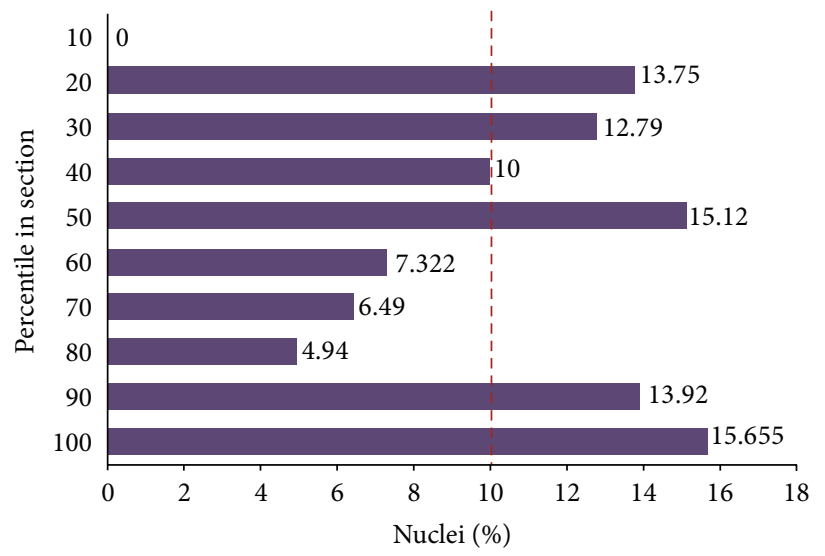

(c)

FIGURE 1: Optical disector method. (a) Look-up section of the disector. (b) Reference section. The cells whose nucleoli appeared in the reference section and did not touch the left and lower borders of the frame were counted. (c) The plot of the $z$-axis distribution of the nuclei. Each histogram indicates the percentile of the counted nuclei in ten percent of the section thickness.

the volume of the mPFC was estimated by the following formula:

$$
V(\mathrm{mPFC})=\sum P\left(\frac{a}{p}\right) d,
$$

where " $\sum P$ " was the total points hitting the $\mathrm{mPFC}$ sections (here 99-135 points per animal), " $a / p$ " was the area associated with each point (here was $0.1 \mathrm{~mm}^{2}$ ), and " $d$ " was the distance between the sampled sections.

The volume density of the vessels and their lumens, " $V_{v}$ (vessels/mPFC)," was estimated using point-counting method and the following formula $[18,19]$ :

$$
V_{v}(\text { vessels } / \mathrm{mPFC})=\frac{P(\text { vessels })}{P(\mathrm{mPFC})},
$$

where " $P$ (vessels)" and " $P(\mathrm{mPFC})$ " represented the total number of the points on the vessels profile and the mPFC, respectively. The total volume was estimated by multiplying the $V_{v}($ vessels/mPFC) by $V(\mathrm{mPFC})[18,19]$.

2.4. Estimation of the Number of Neurons and Glia. The total number of the neurons and glial cells was determined using the optical disector method at the final magnification of $3400 \mathrm{x}$ on $26 \mu \mathrm{m}$ thickness sections [18, 19]. A 100x oil immersion objective lens was used, as well. The location of the microscopic fields was carefully chosen by systematic uniform random sampling while moving the stage in identical distances in $x$ - and $y$-directions. An unbiased counting frame with inclusion and exclusion borders was overlaid on the images of the computer monitor to avoid the "edge effect" and biased counting of the cells (Figure 1). The focal plane of the microscope was moved downwards in $z$-direction. A microcator was attached to the stage of the microscope to measure the $z$-axis movement in depth of the section. The upper and lower guard zones were considered to avoid counting the cutting artifacts located at the upper and lower surfaces of the tissue sections. The height of the disector was demarcated as the section thickness excluding the $4 \mu \mathrm{m}$ thick guard zones at the top and bottom of each section. Any nucleolus (neurons) or nucleus (glial cells) coming into maximal focus within the height of the disector was selected if it lay completely or partly inside the counting frame and did not hit the exclusion lines (Figure 1). The suitable guard zone was defined after estimating the percent of nuclei in the ten columns of the $z$-axis thickness [20]. Each column represented 10 percent of the section thickness. According to the histogram, the upper and lower $20 \%$ were considered as the guard zones. Besides, the remaining columns were considered as the height of the disector (Figure 1). The 
numerical density $\left(N_{v}\right)$ was estimated using the following formula $[18,19]$ :

$$
N_{v}=\frac{\sum Q}{\left[\left(\sum P(a / f) h\right)\right]}\left[\left(\frac{t}{\mathrm{BA}}\right)\right],
$$

where " $\sum Q$ " was the number of the neurons or glial cells nuclei coming into focus and counted (on the average, 80101 neurons and 100-136 glial cells were counted per mPFC), " $\sum P$ " was the total number of the counting frames in all fields, " $a / f$ " was the area per frame $\left(470 \mu \mathrm{m}^{2}\right)$, " $h$ " was the height of the disector, " $t$ " was the real section thickness measured using the microcator when the $Q$ was counted (here $\sim 20 \mu \mathrm{m}$ on the average), and "BA" was the block advance of the microtome which was set at $26 \mu \mathrm{m}$. The total number of the neurons was estimated by multiplying the numerical density $\left(N_{v}\right)$ by $V(\mathrm{mPFC})[18,19]$.

2.5. Estimation of the Coefficient of Error $(C E)$. The $\mathrm{CE}(V)$ for the estimate of the $\mathrm{mPFC}$ volume was calculated using the following formula $[18,19]$ :

$$
\begin{aligned}
\mathrm{CE} & (V)=\left(\sum P\right)^{-1} \\
\cdot & {\left[\frac{1}{240}\left(3 \sum P_{i}^{2}+\sum P_{i} P_{i+2}-4 \sum P_{i} P_{i+1}\right)\right.} \\
+ & \left.0.0724 \cdot \frac{b}{\sqrt{a}} \cdot \sqrt{n \sum P_{i}}\right]^{1 / 2},
\end{aligned}
$$

where " $b$ " and " $a$ " represented the mean section boundary length and mean sectional area, respectively. The CE for the estimate of the total number of neurons, $\mathrm{CE}(N)$, was calculated using $\mathrm{CE}(V)$ and $\mathrm{CE}\left(N_{v}\right)$ as follows:

$$
\begin{aligned}
& \mathrm{CE}(N)=\left[\mathrm{CE}^{2}\left(N_{v}\right)+\mathrm{CE}^{2}(V)\right]^{1 / 2} \\
& \mathrm{CE}\left(N_{v}\right)=\left[( \frac { n } { n - 1 } ) \left[\left(\frac{\sum\left(Q^{-}\right)^{2}}{\left(\sum Q^{-}\right)^{2}}\right)+\left(\frac{\sum(P)^{2}}{\left(\sum P\right)^{2}}\right)\right.\right. \\
& \left.\left.\quad-\left(\frac{2 \sum\left(Q^{-} P\right)}{\sum Q^{-} \sum P}\right)\right]\right]^{1 / 2} .
\end{aligned}
$$

2.6. Statistical Analysis. The study data were entered into the SPSS statistical software (version 15.0) and analyzed using Kruskal-Wallis and Mann-Whitney $U$ test with adjusted alpha level. $P \leq 0.05$ was considered statistically significant.

\section{Results}

3.1. Volume of the mPFC and Its Parts. CE was 0.03 for estimation of the volume of the mPFC that shows acceptable value. The study results revealed $\sim 17 \%$ decrease in the volume of the $\mathrm{mPFC}$ in the $\mathrm{Al}$ group in comparison to the control rats $(P<0.02)$ (Figure 2$)$. However, no improvement was seen in $\mathrm{Al}+\mathrm{PIO}$ group in comparison to the $\mathrm{AL}$ ones. The volume of the ACC reduced by $22 \%$ in the Al-treated rats in comparison to the control ones $(P<0.02)$. However, no significant difference was observed between the $\mathrm{Al}+\mathrm{PIO}$ and $\mathrm{Al}$ groups regarding the volume of the ACC (Figure 2). The study findings showed $\sim 13 \%$ reduction in the volume of the prelimbic region in the Al group in comparison to the control animals $(P<0.02)$ (Figure 2$)$. Nonetheless, no amelioration was detected in the PL volume in the $\mathrm{Al}+\mathrm{PIO}$ group in comparison to the AL rats. The study results revealed $\sim 38 \%$ decrease in the volume of the infralimbic region in the Altreated rats in comparison to the control ones $(P<0.02)$ (Figure 2). Nevertheless, the volume of the infralimbic region remained unchanged in the $\mathrm{Al}+\mathrm{PIO}$-treated rats compared to the Al-treated animals. The volume of the vessels reduced by $47 \%$ in the Al-treated rats in comparison to the control ones $(P<0.02)$. However, no improvement was found in the vessels' volume in the $\mathrm{Al}+\mathrm{PIO}$ group compared to the $\mathrm{Al}$ treated rats (Figure 2).

3.2. Total Number of the Neurons and Glia. CE was 0.11 and 0.12 for estimation of the number of neurons and number of glial cells, respectively, which shows acceptable values. The results showed that the total number of the neurons in the $\mathrm{mPFC}$ was significantly reduced by $40 \%$ in the $\mathrm{Al}$ group in comparison to the control rats $(P<0.02)$. However, the number of the neurons was significantly higher in the $\mathrm{Al}+$ PIO group in comparison to the Al-treated animals. Although there was a difference between the control and Al groups, PIO ameliorated the effects of $\mathrm{Al}$ on reduction of the number of neurons. In other words, the number of the neurons reduced in the $\mathrm{Al}+\mathrm{PIO}$ group, but to a lesser extent compared to $\mathrm{Al}$ alone $(P<0.02)$ (Figure 2$)$. The results showed that the total number of the glial cells in the mPFC was significantly reduced by $25 \%$ in the $\mathrm{Al}$ group in comparison to the control rats $(P<0.02)$. Yet, further analysis revealed no improvement in the $\mathrm{Al}+\mathrm{PIO}$ animals (Figure 2).

3.3. Qualitative Evaluation. As Figure 3 depicts, compared to the control rats, accumulation of the neurons and glia was lesser in the Al-treated animals in both superficial and deep layers of the mPFC. More population of the cells was detected after the concomitant treatment of the rats with $\mathrm{PIO}$ and $\mathrm{Al}$ in comparison to administration of $\mathrm{Al}$ in the layers of the cortex.

\section{Discussion}

The present study evaluated the effects of $\mathrm{Al}$ on the structure of the mPFC of the rats using stereological methods. The protective effects of PIO on the Al-treated rats were investigated, as well. Reduction of the volume of $\mathrm{MPFC}$ and its subdivisions was the finding of the first step of this survey. The cortex volume reduction is in coincidence with the work of Stoeckel et al., (2013). Their MRI findings suggested medial frontal cortex atrophy in patients with mild Alzheimer disease [21].

Cerebral cortex including $\mathrm{mPFC}$ is composed of neurons, glial cells, vessels, and neuropil. The vessels volume mainly reflects the blood volume that can fill the vessels and, therefore, the blood supply of the tissue. This parameter has received less attention in Al-exposure before. Our study 


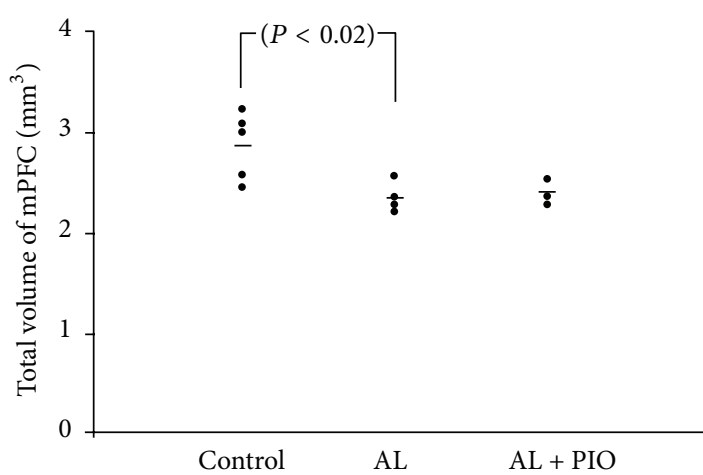

(a)

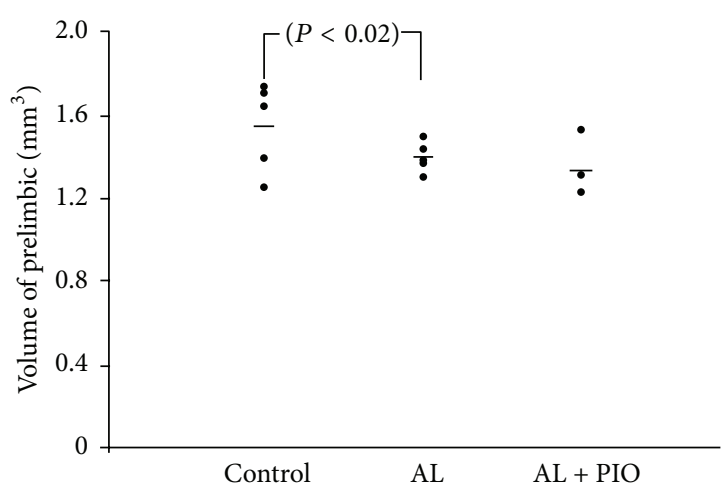

(c)

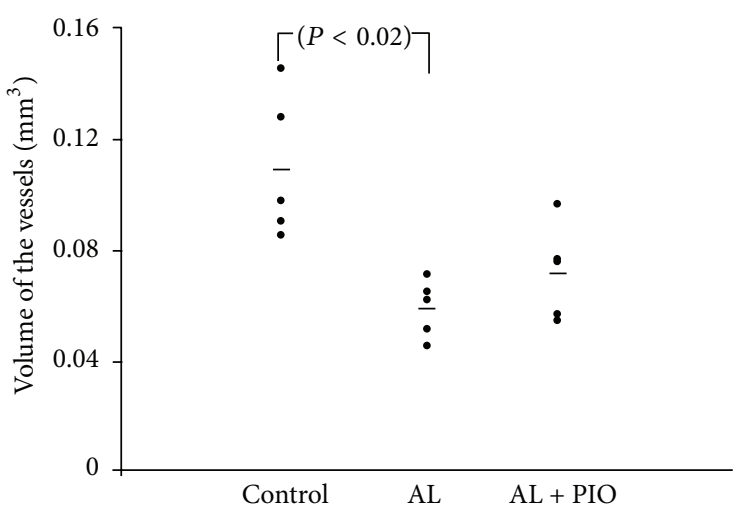

(e)

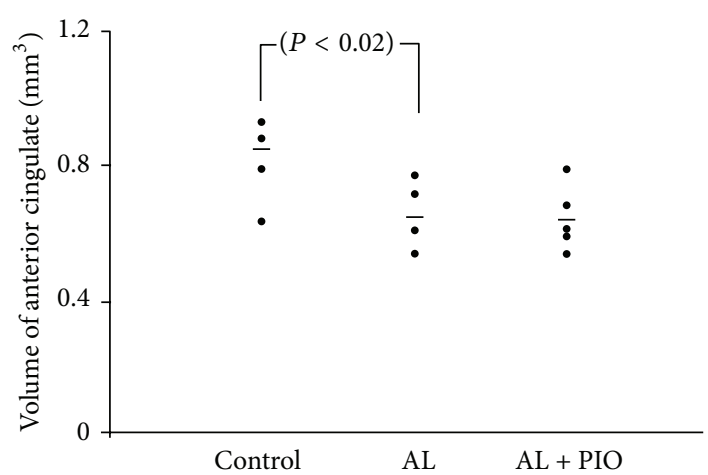

(b)

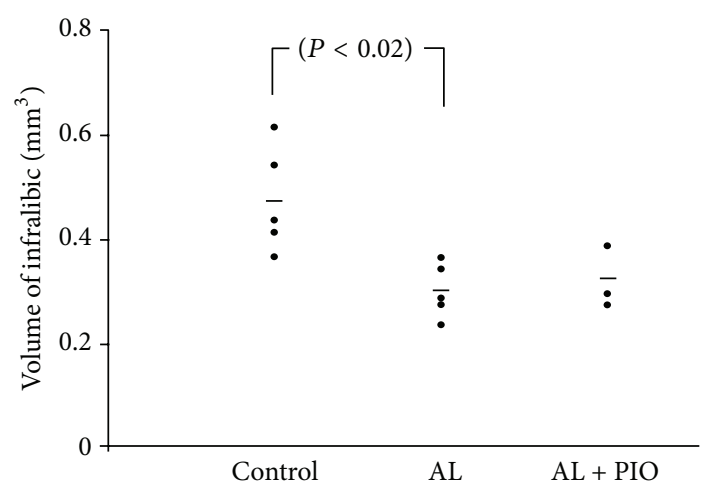

(d)

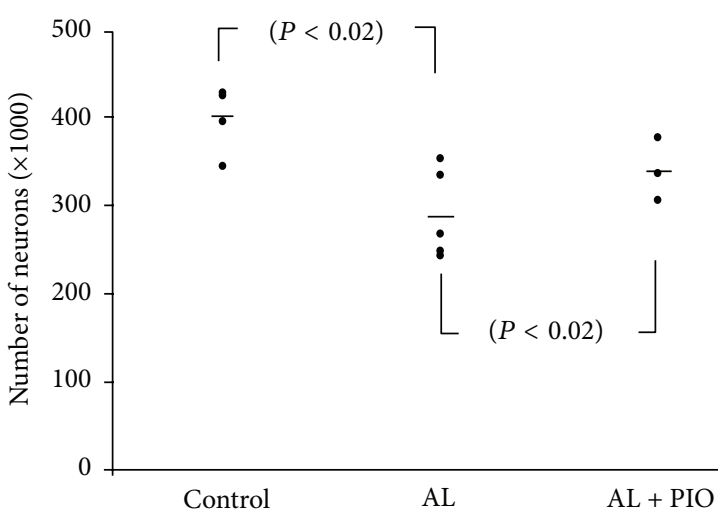

(f)

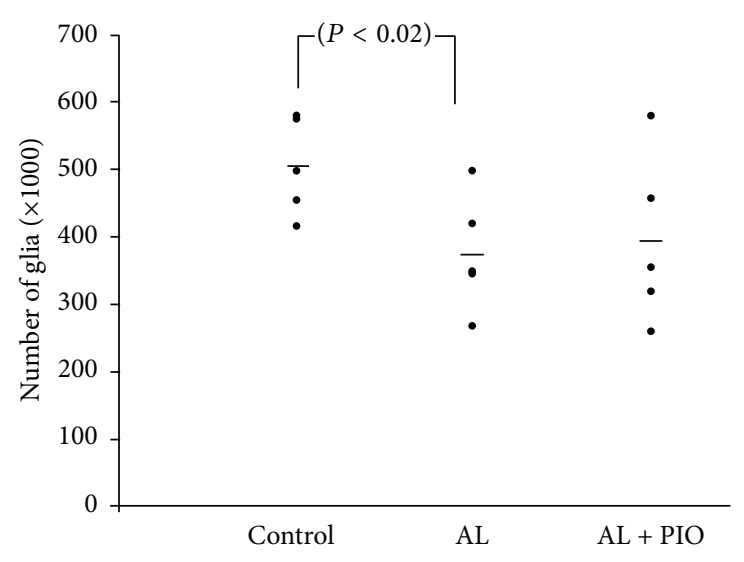

(g)

FIGURE 2: The scattered plots of the total volume of the mPFC (a), anterior cingulate cortex (b), prelimbic cortex (c), infralimbic cortex (d), vessels (e), number of neurons (f), and number of glial cells ( $\mathrm{g}$ ) in the control, $\mathrm{Al}$, and $\mathrm{Al}+\mathrm{PIO}$ groups. 


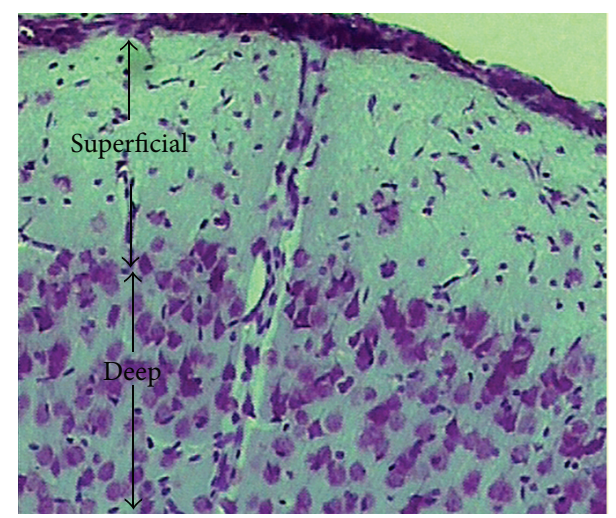

(a)

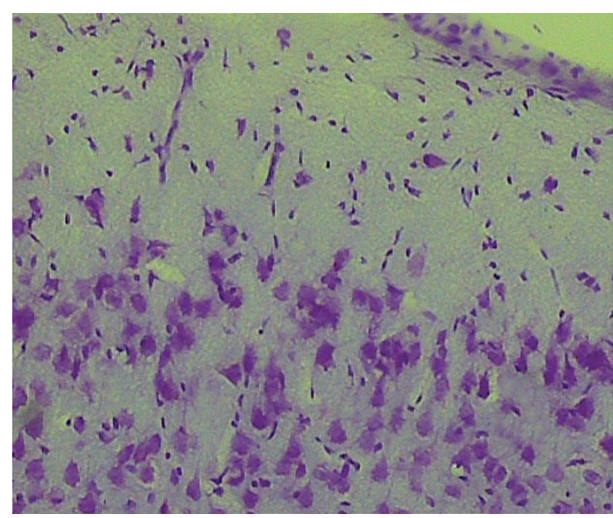

(b)

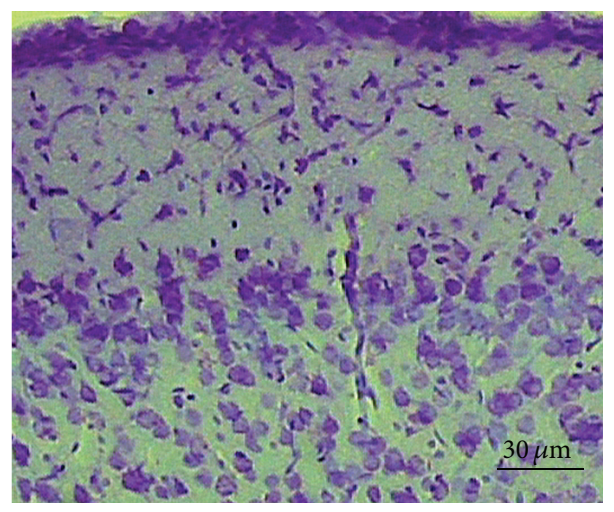

(c)

FIGURE 3: Photomicrograph of the mPFC in the rats. (a) Control, (b) Al-treated, and (c) Al + PIO-treated groups. The difference between the cells population in the superficial and deep layers of the cortex can be observed in the groups.

results showed that this parameter was decreased after Altreatment in the rats. Our finding in regard of vessels density coincides with Chen et al. (2013) who evaluated the brain changes using MRI and estimation of cerebral blood flow [22]. They reported that regional cerebral blood flow and the density of the vessels are reduced after $\mathrm{AlCl}_{3}$-induced Alzheimer disease in rats [22]. Their results showed that in these animals most vessels around the hippocampus and cortex could not be observed [22]. The results obtained by Bhattacharjee et al. (2013) suggested that the endothelial cells that lined the cerebral vasculature might have biochemical properties leading to binding of $\mathrm{Al}$ to them [23]. There are researches that suggested that cerebral hypoxia triggers the potential downstream inflammatory and pathogenic consequences [23, 24]. Therefore, the above-mentioned studies might explain the reduction of the vessels' volume in the present study.

Another finding of this study was loss of neurons and glial cells. These findings were in agreement with those obtained in the previous studies, demonstrating that $\mathrm{Al}$ added to the diet was able to induce neuron and glia loss and Alzheimer's disease $[25,26]$. The evidences of Walton (2009) suggested aluminum progressively collects in cortical and limbic areas of vulnerable subjects' brains, eventually producing cell loss and disrupting afferent and efferent circuitry [27].
Previous studies claimed that glial cells might be one of the targets of Al neurotoxicity [5]. Reduction of the vessels' volume and consequently the blood supply might be one of the reasons for the cell loss in the Al-exposed rats. In addition, Bhattacharjee et al. (2014) reported disruption in the blood brain barrier in the vessels of the nervous system after $\mathrm{Al}$ toxicity [26] that might be followed by Al distribution in the brain tissue. AL toxicity may finally lead to degradation of the cells. Apoptosis and necrosis are the main mechanism of cell death in Al toxicity [28, 29].

The results of the current study confirmed that pioglitazone diminished neurodegeneration caused by Al. Up to now, a limited number of studies have indicated the structural protection of PIO and most studies have focused on behavioral improvement by PIO. The neuroprotective results of the current study were consistent with a previous evaluation of the neuroprotective effects of PIO, in which $30 \mathrm{mg} / \mathrm{kg}$ PIO administration in a rat model of Parkinsonism protected the neurons [30]. Additionally, Pang et al. (2014) conducted an in vitro study and demonstrated that PIO could protect the rats' cerebellar granule cells against nutrient deprivation [31]. Moreover, R. Gupta and L. K. Gupta (2012) demonstrated that PIO offered protection against memory dysfunctions observed in Alzheimer's model [32]. They suggested that the protective action of PIO was possibly due to its 
antioxidant action. One other study also confirmed that PIO had a neuroprotective effect against scopolamine-induced cholinergic system deficit and cognitive impairment [33]. PIO is essentially used for management of diabetes mellitus type 2 either alone or in combination with other drugs [30-33]. PIO decreases blood sugar levels. Yet, neuroprotection should be added to its effects, as well. The mechanism of action of PIO might be due to its anti-inflammatory process. It has been suggested that PIO inhibits the inflammatory response by attenuating the mediators of inflammation, including expression of cyclooxygenase-2, (an enzyme responsible for inflammation, COX-2), prostaglandin E2 generation (a bioactive lipid that provokes an extensive range of biological effects associated with inflammation, PGE2), and microglia activation, resulting in protection of neurons [30-33].

\section{Conclusion}

In conclusion, $\mathrm{Al}$ could induce structural changes in the rats' $\mathrm{mPFC}$. Besides, pioglitazone showed beneficial effects on neuronal protection in the Al-exposed animals.

\section{Disclosure}

This study was extracted from the thesis written by Hajar Yazdani, M.S. degree student of physiology.

\section{Conflict of Interests}

The authors declare that they have no competing interests.

\section{Authors' Contribution}

Ali Rafati was the supervisor of the study. Hajar Yazdani carried out the stereological studies. Ali Noorafshan designed and prepared the draft of the paper. All authors read and approved the final paper.

\section{Acknowledgments}

The work was financially supported by the research vicechancellor of the university (Grant no. 92-6789). The authors would like to appreciate Rouz Darou Pharmaceutical Company for the kind provision of pioglitazone. They are also grateful to Ms. A. Keivanshekouh at the Research Improvement Center for improving the use of English in the paper.

\section{References}

[1] J. R. Walton, "Chronic aluminum intake causes Alzheimer's disease: applying sir austin bradford hill's causality criteria," Journal of Alzheimer's Disease, vol. 40, no. 4, pp. 765-838, 2014.

[2] V. Kumar and K. D. Gill, "Oxidative stress and mitochondrial dysfunction in aluminium neurotoxicity and its amelioration: a review," NeuroToxicology, vol. 41, pp. 154-166, 2014.

[3] Y. Yase, S. Yoshida, T. Kihira, I. Wakayama, and J. Komoto, "Kii ALS dementia," Neuropathology, vol. 21, no. 2, pp. 105-109, 2001.
[4] J. K. Seamans, C. C. Lapish, and D. Durstewitz, "Comparing the prefrontal cortex of rats and primates: insights from electrophysiology," Neurotoxicity Research, vol. 14, no. 2-3, pp. 249-262, 2008.

[5] S. X. Guo-Ross, E. Y. Yang, T. J. Walsh, and S. C. Bondy, "Decrease of glial fibrillary acidic protein in rat frontal cortex following aluminum treatment," Journal of Neurochemistry, vol. 73, no. 4, pp. 1609-1614, 1999.

[6] K. Kim, "Perinatal exposure to aluminum alters neuronal nitric oxide synthase expression in the frontal cortex of rat offspring," Brain Research Bulletin, vol. 61, no. 4, pp. 437-441, 2003.

[7] I. Aviles-Olmos, P. Limousin, A. Lees, and T. Foltynie, "Parkinson's disease, insulin resistance and novel agents of neuroprotection," Brain, vol. 136, no. 2, pp. 374-384, 2013.

[8] J. Zhu, J. Zhang, M. Ji et al., "The role of peroxisome proliferatoractivated receptor and effects of its agonist, pioglitazone, on a rat model of optic nerve crush: PPAR $\gamma$ in retinal neuroprotection," PLoS ONE, vol. 8, no. 7, Article ID e68935, 2013.

[9] H.-B. Jia, X.-M. Wang, L.-L. Qiu et al., "Spinal neuroimmune activation inhibited by repeated administration of pioglitazone in rats after L5 spinal nerve transection," Neuroscience Letters, vol. 543, pp. 130-135, 2013.

[10] R. Bordet, T. Ouk, O. Petrault et al., "PPAR: a new pharmacological target for neuroprotection in stroke and neurodegenerative diseases," Biochemical Society Transactions, vol. 34, no. 6, pp. 1341-1346, 2006.

[11] F. Gofflot, N. Chartoire, L. Vasseur et al., "Systematic gene expression mapping clusters nuclear receptors according to their function in the brain," Cell, vol. 131, no. 2, pp. 405-418, 2007.

[12] D. M. Hyde, N. K. Tyler, and C. G. Plopper, "Morphometry of the respiratory tract: avoiding the sampling, size, orientation, and reference traps," Toxicologic Pathology, vol. 35, no. 1, pp. 4148, 2007.

[13] P. Nayak, S. B. Sharma, and N. V. S. Chowdary, "Aluminum and ethanol induce alterations in superoxide and peroxide handling capacity (SPHC) in frontal and temporal cortex," Indian Journal of Biochemistry and Biophysics, vol. 50, no. 5, pp. 402-410, 2013.

[14] V. Fekete, S. Vandevijvere, F. Bolle, and J. van Loco, "Estimation of dietary aluminum exposure of the Belgian adult population: evaluation of contribution of food and kitchenware," Food and Chemical Toxicology, vol. 55, pp. 602-608, 2013.

[15] M. Almasi-Nasrabadi, M. Javadi-Paydar, S. Mahdavian et al., "Involvement of NMDA receptors in the beneficial effects of pioglitazone on scopolamine-induced memory impairment in mice," Behavioural Brain Research, vol. 231, no. 1, pp. 138-145, 2012.

[16] J. Wang, "Current researches on biological effect of aluminum," Wei Sheng Yan Jiu, vol. 31, no. 4, pp. 320-322, 2002.

[17] G. Paxinos and C. Watson, Eds., The Rat Brain in Stereotaxic Coordinates, Academic Press, San Diego, Calif, USA, 6th edition, 2006.

[18] S. L. B. Kristiansen and J. R. Nyengaard, "Digital stereology in neuropathology," APMIS, vol. 120, no. 4, pp. 327-340, 2012.

[19] C. Schmitz and P. R. Hof, "Design-based stereology in neuroscience," Neuroscience, vol. 130, no. 4, pp. 813-831, 2005.

[20] C. S. von Bartheld, "Distribution of particles in the Z-axis of tissue sections: relevance for counting methods," NeuroQuantology, vol. 10, no. 1, pp. 66-75, 2012.

[21] L. E. Stoeckel, C. C. Stewart, H. R. Griffith et al., "MRI volume of the medial frontal cortex predicts financial capacity in patients 
with mild Alzheimer's disease," Brain Imaging and Behavior, vol. 7, no. 3, pp. 282-292, 2013.

[22] S.-M. Chen, C.-C. Fan, M.-S. Chiue, C. Chou, J.-H. Chen, and R.-S. Hseu, "Hemodynamic and neuropathological analysis in rats with aluminum trichloride-induced Alzheimer's disease," PLoS ONE, vol. 8, no. 12, Article ID e82561, 2013.

[23] S. Bhattacharjee, Y. Zhao, J. M. Hill et al., "Selective accumulation of aluminum in cerebral arteries in Alzheimer's disease (ad)," Journal of Inorganic Biochemistry, vol. 126, pp. 35-37, 2013.

[24] L. Chen, B. Zhang, and M. Toborek, "Autophagy is involved in nanoalumina-induced cerebrovascular toxicity," Nanomedicine: Nanotechnology, Biology, and Medicine, vol. 9, no. 2, pp. 212-221, 2013.

[25] A. F. Silva Jr., M. S. S. Aguiar, O. S. Carvalho Jr. et al., "Hippocampal neuronal loss, decreased GFAP immunoreactivity and cognitive impairment following experimental intoxication of rats with aluminum citrate," Brain Research, vol. 1491, pp. 2333, 2013.

[26] S. Bhattacharjee, Y. Zhao, J. M. Hill, M. E. Percy, and W. J. Lukiw, "Aluminum and its potential contribution to Alzheimer's disease (AD)," Frontiers in Aging Neuroscience, vol. 6, article 62, 2014.

[27] J. R. Walton, "Brain lesions comprised of aluminum-rich cells that lack microtubules may be associated with the cognitive deficit of Alzheimer's disease," NeuroToxicology, vol. 30, no. 6, pp. 1059-1069, 2009.

[28] Q. L. Zhang, P. Boscolo, P. Y. Niu et al., "How do rat cortical cells cultured with aluminum die: necrosis or apoptosis?" International Journal of Immunopathology and Pharmacology, vol. 21, no. 1, pp. 107-115, 2008.

[29] D. V. Krysko, T. Vanden Berghe, K. D’Herde, and P. Vandenabeele, "Apoptosis and necrosis: detection, discrimination and phagocytosis," Methods, vol. 44, no. 3, pp. 205-221, 2008.

[30] J. K. Barbiero, R. M. Santiago, D. S. Persike et al., "Neuroprotective effects of peroxisome proliferator-activated receptor alpha and gamma agonists in model of parkinsonism induced by intranigral 1-methyl-4-phenyl-1,2,3,6-tetrahyropyridine," Behavioural Brain Research, vol. 274, pp. 390-399, 2014.

[31] T. Pang, L. X. Sun, T. Wang, Z. Z. Jiang, H. Liao, and L. Y. Zhang, "Telmisartan protects central neurons against nutrient deprivation-induced apoptosis in vitro through activation of PPAR $\gamma$ and the Akt/GSK-3 $\beta$ pathway," Acta Pharmacologica Sinica, vol. 35, no. 6, pp. 727-737, 2014.

[32] R. Gupta and L. K. Gupta, "Improvement in long term and visuo-spatial memory following chronic pioglitazone in mouse model of Alzheimer's disease," Pharmacology Biochemistry and Behavior, vol. 102, no. 2, pp. 184-190, 2012.

[33] G. Q. Xiang, S. S. Tang, L. Y. Jiang et al., "PPAR $\gamma$ agonist pioglitazone improves scopolamine-induced memory impairment in mice," Journal of Pharmacy and Pharmacology, vol. 64, no. 4, pp. 589-596, 2012. 


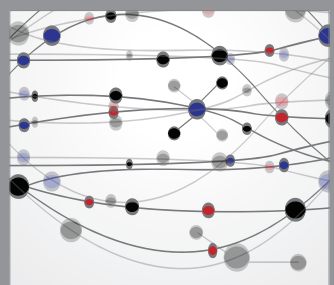

The Scientific World Journal
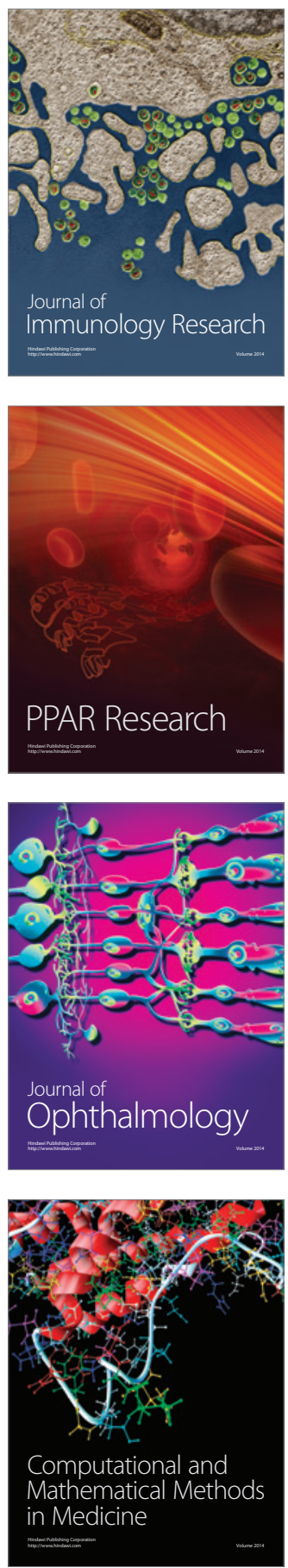

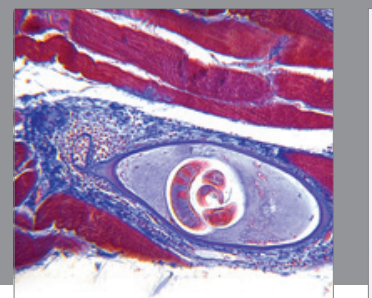

Gastroenterology

Research and Practice
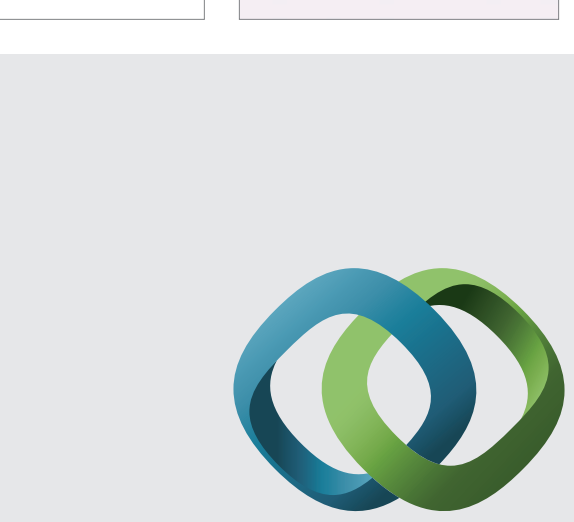

\section{Hindawi}

Submit your manuscripts at

http://www.hindawi.com
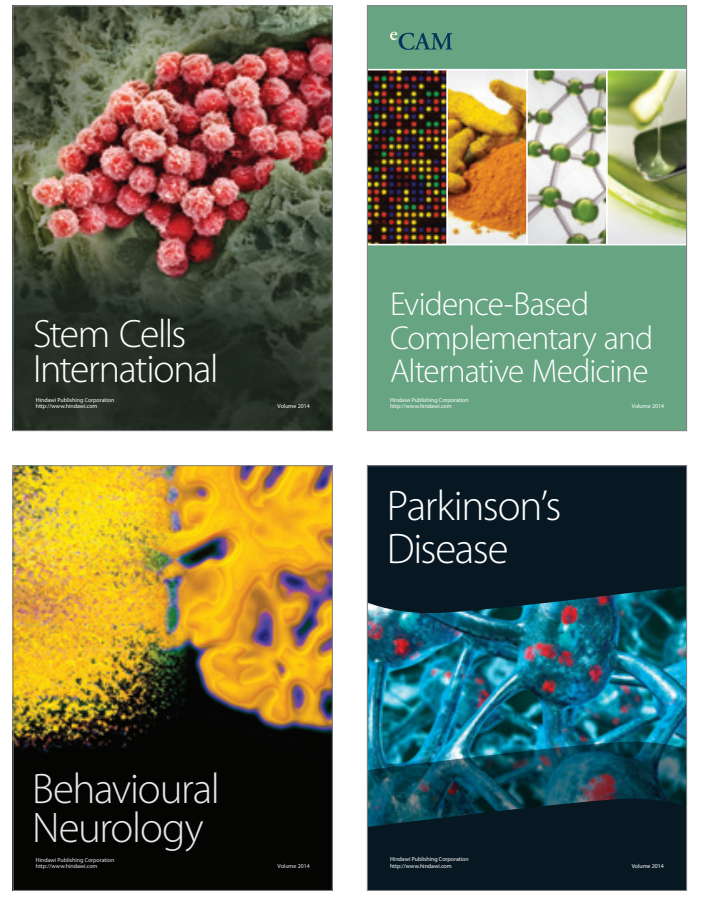
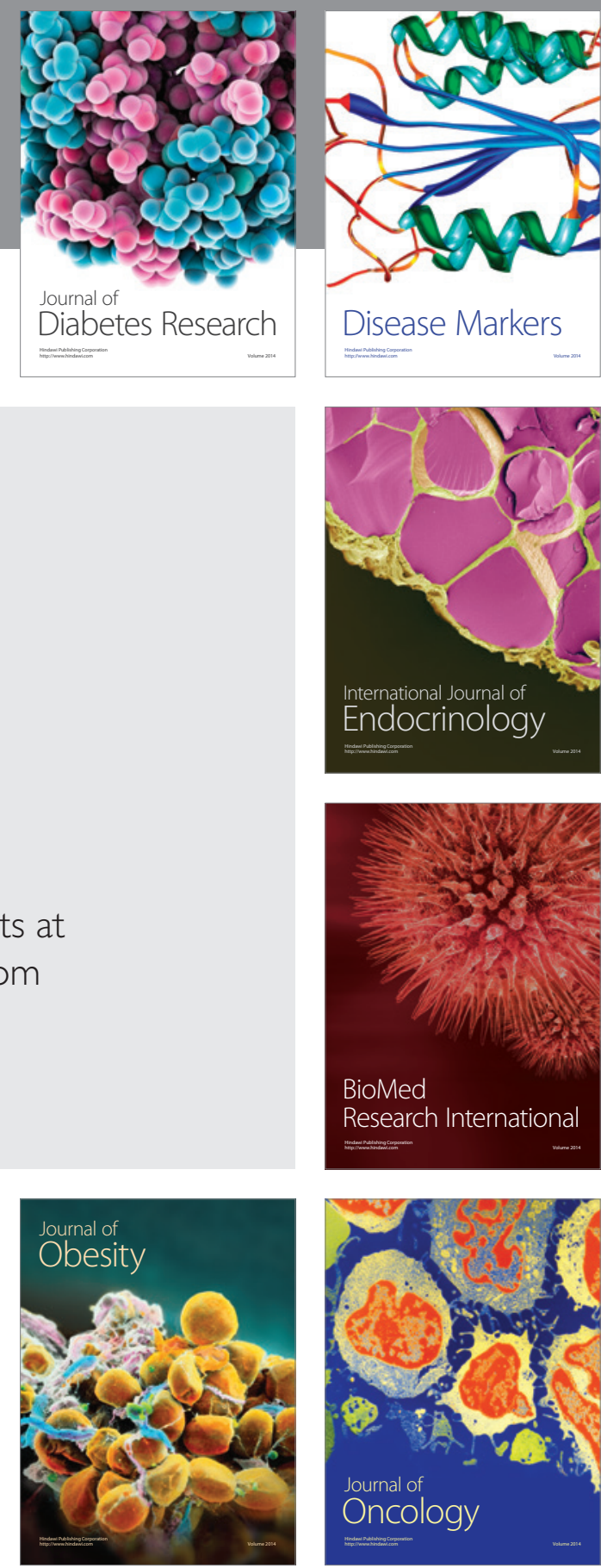

Disease Markers
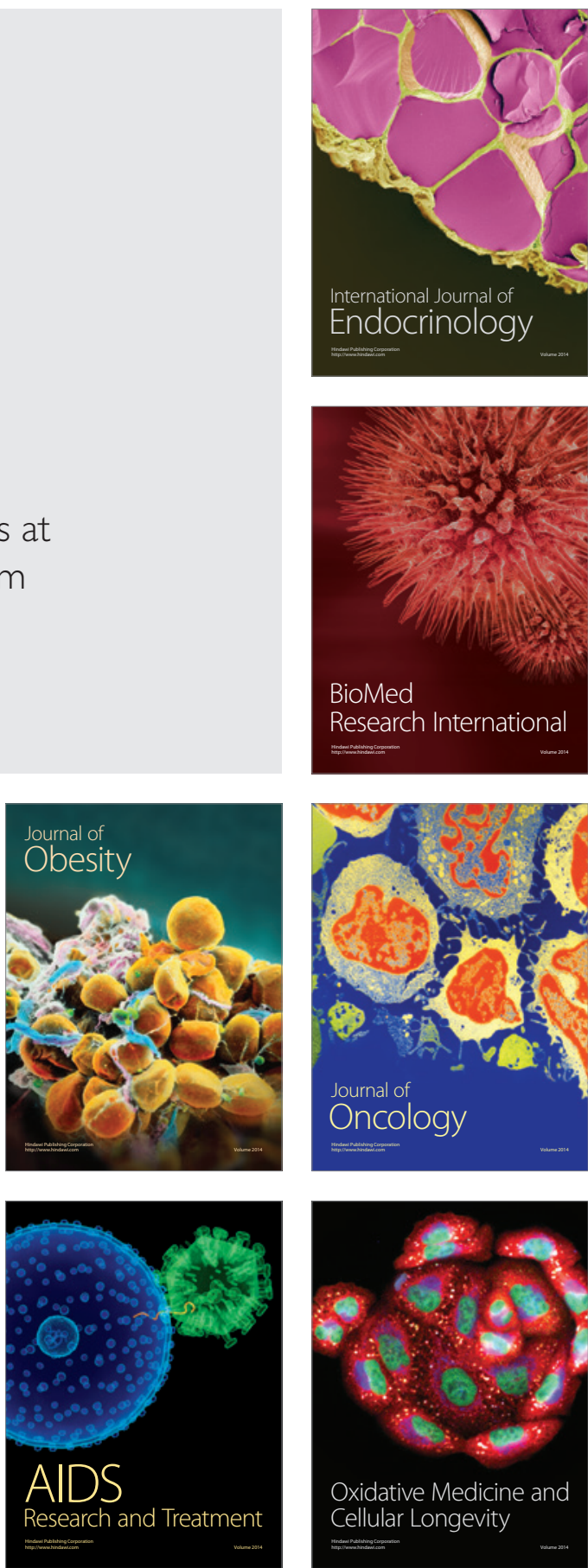